\title{
Successful Endoscopic Ultrasound-Guided Alcohol Ablation of Sporadic Insulinoma Using Three-Dimensional Targeting (with Video)
}

\author{
Guru Trikudanathan, Shawn J. Mallery and Stuart K. Amateau \\ Division of Gastroenterology, Department of Medicine, University of Minnesota, Minneapolis, MN, USA
}

Surgical resection is considered the standard of care in the management of symptomatic insulinoma. In this video, we describe the successful management of a symptomatic insulinoma by using linear array endoscopic ultrasound (EUS)-guided ethanol ablation in a poor surgical candidate. EUS-guided ethanol ablation of insulinoma offers a safer, effective, and less invasive alternative to surgery.

Clin Endosc 2016;49:399-401

Key Words: Insulinoma; Endoscopic ultrasound-guided alcohol ablation

\section{INTRODUCTION}

Insulinoma is the most common functional islet-cell tumor of the pancreas. ${ }^{1,2}$ While surgical enucleation or resection is the standard of care, alternative management options may be mandated in symptomatic patients with unresectable disease, or for poor surgical candidates. We present a successful management of symptomatic insulinoma using endoscopic ultrasound (EUS)-guided ethanol ablation in a poor surgical candidate.

\section{CASE REPORT}

A 66-year-old Caucasian man with decompensated heart failure, asthma, chronic obstructive pulmonary disease, post-traumatic stress disorder, and atrial fibrillation on

Received: November 3, 2015 Accepted: January 27, 2016

Correspondence: Stuart K. Amateau

Division of Gastroenterology, Department of Medicine, University of Minnesota, 406 Harvard St SE, MMC36, Minneapolis, MN 55455, USA

Tel: +1-612-625-3128, Fax: +1-612-625-5620, E-mail: amateau@umn.edu

(cc) This is an Open Access article distributed under the terms of the Creative Commons Attribution Non-Commercial License (http://creativecommons.org/ licenses/by-nc/3.0) which permits unrestricted non-commercial use, distribution, and reproduction in any medium, provided the original work is properly cited. anti-coagulation was initially referred for management of post-cholecystectomy biliary strictures, which were treated with endoscopic retrograde cholangiopancreatography, and placement of biliary stents. Magnetic resonance imaging performed at that time showed an incidental pancreatic head mass. Subsequently, he underwent (EUS), which demonstrated a $14 \times 12 \mathrm{~mm}$, well defined, hypoechoic lesion within the pancreatic head. EUS-guided fine needle aspiration demonstrated a monomorphic population of neoplastic cells diffusely and strongly positive for CD56, synaptophysin, and chromogranin, compatible with a neuroendocrine tumor (Fig. 1). An octreotide scan showed no evidence of metastatic disease. As the patient was asymptomatic, he was followed conservatively for a non-functioning insulinoma. Six months later, however, the patient was triaged for fasting hypoglycemia (blood sugar levels as low as $45 \mathrm{mg} / \mathrm{dL}$ ) in tandem with neuroglycopenic symptoms. His C-peptide level was noted to be 7.47 (normal range, 0.80 to 3.85 ) and his insulin level was $32.8 \mathrm{mIU} / \mathrm{L}$ (normal range, 1.9 to 23.0 ) at the time of hypoglycemia, consistent now with a functioning insulinoma, prompting intervention. Medical therapy with diazoxide (50 mg twice daily) resulted in hypotension, and acute kidney injury necessitating discontinuation. Treatment with octreotide (150 mcg subcutaneously three times daily) did not resolve the hypoglycemic episodes. Although the tumor was resectable, the patient was deemed 


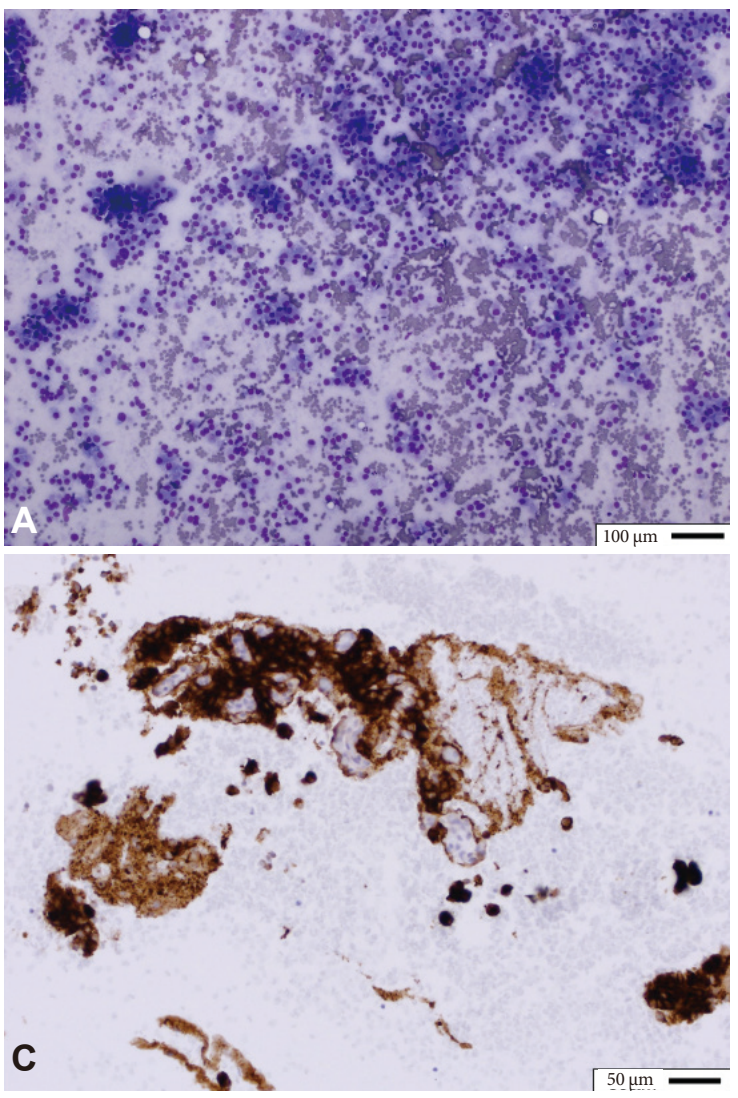

inappropriate for surgery due to his comorbidities. EUS-guided ethanol ablation was therefore considered. The lesion was injected with $1 \mathrm{~mL}$ of ethanol (in 4 divided doses) using three-dimensional targeting, resulting in a hyperechoic blush within the margins of the tumor (Supplementary Video 1). Following the procedure, the patient's fasting glucose, insulin level, and C-peptide normalized. He had no post-procedural complications or further hypoglycemic attacks throughout 6 weeks of follow-up, confirming complete remission.

\section{DISCUSSION}

Surgical enucleation of tumor, the mainstay of treatment for sporadic insulinoma is associated with a high morbidity (10\% to $43 \%$ ) and a mortality of up to $4 \%$, particularly in the elderly, and those with comorbid conditions. ${ }^{1-3}$ EUS-guided ethanol ablation of insulinoma offers a safe, effective, and less invasive alternative to surgery with shorter hospital admissions. ${ }^{2,3}$ It has been primarily viewed as an intervention aimed at symptomatic amelioration rather than definitive oncologic therapy. ${ }^{2}$ It has also been suggested as an option in recurrent or metastatic insulinoma, where re-operation or radical resection is challenging. ${ }^{2-4}$ Post-procedural complications include mild pancreatitis as well as medically con-

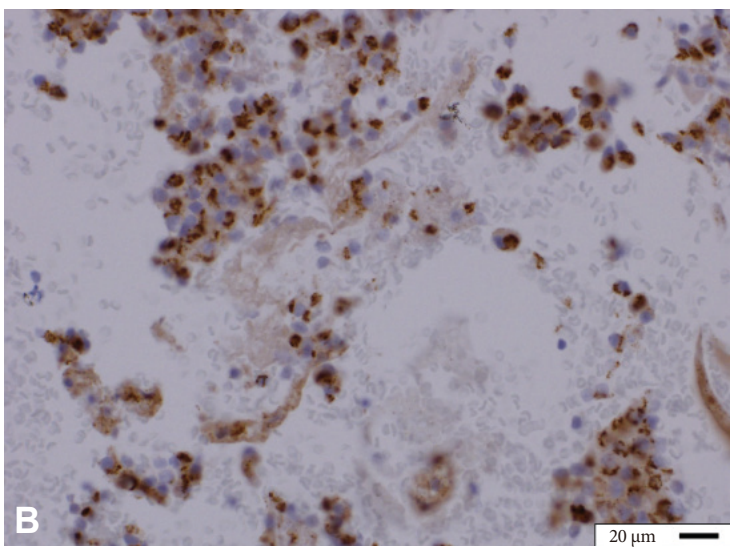

Fig. 1. (A) Cytologic preparations demonstrate a monomorphous population of neoplastic cells with neuroendocrine features Diff-Quik stain $(\times 20)$ highlighting typical 3-dimensional clusters. (B) Chromogranin $(\times 100)$ and $(C)$ synaptophysin immunohistochemical stains both positive for the genetic markers of neuroendocrine differentiation $(\times 40)$.

trolled ulcer, and hematoma of the duodenal wall. ${ }^{5,6}$ This case report adds to only a handful of documented cases treated successfully with EUS-guided ethanol ablation and provides a video demonstrating three dimensional targeting, the latter representing a useful technical approach. Careful patient selection is imperative to optimize outcomes, as small lesions or those in proximity to blood vessels could pose technical difficulties. ${ }^{3}$ The possibility of late relapse needing re-intervention, incomplete ablation, and risk of metastasis are other inherent risks. ${ }^{2}$ Long-term follow-up is needed to determine the enduring benefits of therapy as well as the potential for malignant transformation. ${ }^{2}$

\section{Conflicts of Interest}

SKA serves as a consultant for Boston Scientific, Merit Endoscopy.

\section{Supplementary Material}

Video 1. EUS-guided ethanol ablation of an insulinoma utilizing three-dimensional targeting (http://dx.doi.org/10.5946/ce.2015.144.v001).

\section{REFERENCES}

1. Grover AC, Skarulis M, Alexander HR, et al. A prospective evaluation of laparoscopic exploration with intraoperative ultrasound as a technique for localizing sporadic insulinomas. Surgery 2005;138:1003-1008.

2. Levy MJ, Thompson GB, Topazian MD, Callstrom MR, Grant CS, Vella 
A. US-guided ethanol ablation of insulinomas: a new treatment option. Gastrointest Endosc 2012;75:200-206.

3. Qin SY, Lu XP, Jiang HX. EUS-guided ethanol ablation of insulinomas: case series and literature review. Medicine (Baltimore) 2014;93:e85.

4. Lee MJ, Jung CH, Jang JE, et al. Successful endoscopic ultrasound-guided ethanol ablation of multiple insulinomas accompanied with multiple endocrine neoplasia type 1. Intern Med J 2013;43:948-950.
5. Jürgensen C, Schuppan D, Neser F, Ernstberger J, Junghans U, Stölzel U. EUS-guided alcohol ablation of an insulinoma. Gastrointest Endosc 2006;63:1059-1062.

6. Deprez PH, Claessens A, Borbath I, Gigot JF, Maiter D. Successful endoscopic ultrasound-guided ethanol ablation of a sporadic insulinoma. Acta Gastroenterol Belg 2008;71:333-337. 